\title{
POST-FABRICATION VAPOR PHASE STRENGTHENING OF A NICKEL-BASED SHEET ALLOY FOR THERMOSTRUCTURAL PANELS
}

\author{
S. J. Johnson ${ }^{1}$, R. R. Adharapurapu ${ }^{1}$, T. M. Pollock ${ }^{1}$ \\ ${ }^{1}$ The University of Michigan; Department of Materials Science and Engineering; 3062 HH Dow Building; Ann Arbor, MI, 48109-2136, \\ USA
}

Keywords: Bulk Diffusion, Coating, Annealing, Nickel Alloys.

\begin{abstract}
High temperature metallic systems for use in thermostructural sandwich panels are important for many hypersonic flight systems. The complex three-dimensional geometry of these structures poses fabrication challenges for high-strength, hightemperature alloys. A new processing technique involving postfabrication strengthening via pack aluminization has been developed. A rectangular channeled panel was fabricated by brazing thin, wrought sheet. The aluminization produces a $\beta$ NiAl surface layer, which is decomposed in subsequent annealing treatments, distributing $\mathrm{Al}$ through the thickness of the panel component. Substantial strengthening of the sheet occurs due to the development of a $\gamma-\gamma^{\prime}$ structure through the thickness. Microstructural development through the stages of processing is discussed along with mechanical properties of the postfabrication, precipitation-strengthened sheet.
\end{abstract}

\section{Introduction}

In advanced high Mach number aerospace flight vehicles, there is a need for strong, lightweight, high-temperature capable, and oxidation resistant structures. Metallic, rather than ceramic, panels are desirable for their high damage resistance along with the availability of relatively low cost manufacturing approaches. Metallic structures could be used as inlet panels for scramjet engines and non-leading edge "acreage" panels that must endure demanding high temperature (near $1000{ }^{\circ} \mathrm{C}$ ) oxidizing conditions when operating at up to Mach 8 flight conditions [1-4]. Kagomestructured, prismatic core, or honeycomb thermostructural panels show great promise to fulfill these structural and environmental requirements (examples in Figure 1). The geometry of the panels can be optimized to resist a variety of failure modes. To address the structural and heat flux requirements, the thermostructural panels can be optimized for a combination of mechanical strength and cooling capacity [6]. Therefore, fabrication approaches for a wide range of panel geometries are needed.

Nickel-based superalloys with high volume fractions of $\gamma^{\prime}\left(\mathrm{Ni}_{3} \mathrm{Al}\right)$ precipitates are often used in high-temperature aerospace applications and are conventionally cast into near net shape forms. The thin walls and geometrical complexity of thermostructural panels pose major challenges for conventional investment casting of nickel-based alloys [4]. Although these structures can be fabricated from thin gage sheet materials, most nickel-base alloys available in sheet form have severely limited high temperature creep properties.

(a)

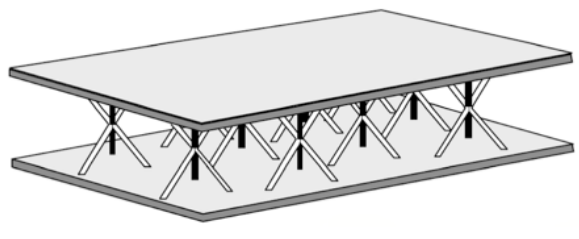

(b)

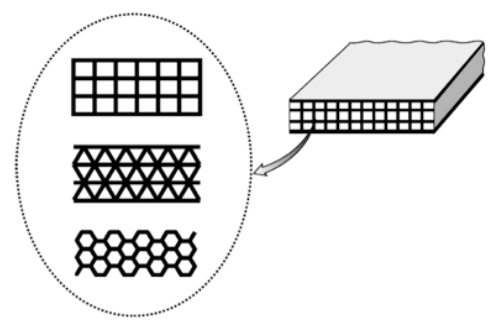

Figure 1. Examples of configurations for thermostructural panels. (a) Kagomé [5]. (b) Prismatic cores [2].

Many refractory-lean $\gamma$-nickel alloys without precipitation hardening are readily processed to thin sheet and shaped at room temperature. By starting with thin wrought sheets of these alloys, it is possible to fabricate panels with the required geometries. It is important to note that in order for these alloys to be used in a thermostructural panel, the high-temperature mechanical properties of these alloys must be improved. This increase in strength will allow for an actively cooled prismatic core panel to be very attractive when optimizing designs that combine structural load capacity with heat dissipation [2]. Precipitation strengthening is the most efficient strengthening approach, but it must not interfere with the sheet processing operations.

To achieve a more optimal combination of high-temperature strength and complex geometrical structure, a processing method that consists of deposition of an aluminide layer with subsequent annealing to drive the aluminum through the sheet thickness has been developed. This process results in precipitation strengthening of the alloy in a post-fabricated state. It is possible to produce the aluminide layer via pack cementation $[7,8]$ and with the resulting concentration gradient of $\mathrm{Al}$, subsequent annealing should result in a homogenization of the Al in the alloy [9]. The feasibility of this approach is demonstrated. 


\section{Experimental Materials and Procedure}

Haynes alloy X-750 wrought sheet was selected for this processing technique due to its high $\mathrm{Cr}$ and low refractory alloy content. The major alloying components are listed in Table 1, with the microstructure shown in Figure 2. The sheet used in this study was $0.635 \mathrm{~mm}$ thick and was cut with wire electrical discharge machining (EDM) into rectangles of dimensions 8.4 $\mathrm{mm} \times 52 \mathrm{~mm}$ for panel webbing and $52 \mathrm{~mm}$ x $52 \mathrm{~mm}$ squares for face sheets. These pieces were hand polished to 600 grit $\mathrm{SiC}$ paper and ultrasonically cleaned in acetone.

Table 1. Nominal compositions of nickel-based alloy X-750 (wt\%) and AMDRY DF-6A braze $[10,11]$

\begin{tabular}{|l|l|l|l|l|l|l|l|l|l|}
\hline & $\mathrm{Ni}$ & $\mathrm{Cr}$ & $\mathrm{Al}$ & $\mathrm{Fe}$ & $\mathrm{Ti}$ & $\mathrm{Nb}$ & $\mathrm{Co}$ & $\mathrm{Ta}$ & $\mathrm{B}$ \\
\hline $\mathrm{X}-750$ & $\mathrm{Bal}$ & 16 & 0.8 & 8 & 1 & 2.5 & 1 & -- & \\
\hline Braze & Bal & 20 & -- & -- & -- & -- & -- & 3 & 3.15 \\
\hline
\end{tabular}

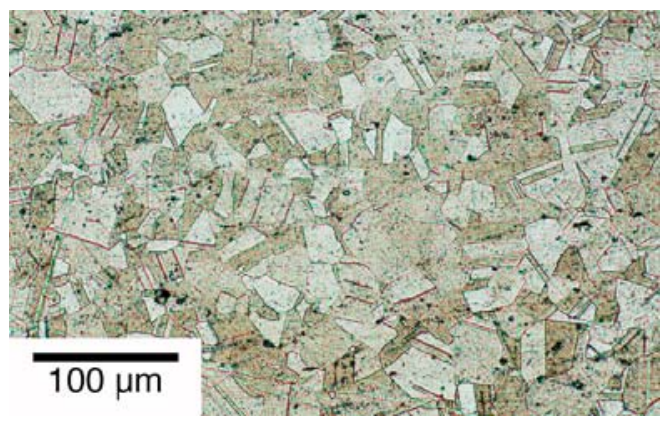

Figure 2. Grain structure of the wrought X-750 sheet.

A $52 \mathrm{~mm} \times 52 \mathrm{~mm} \times 10 \mathrm{~mm}$ panel with rectangular channels was fabricated with the pieces of X-750 sheet and AMDRY DF-6A braze tape (elemental components in Table 1), the cross-section shown in Figure 3. The braze tape was applied to the long edges of the panel webbing and subsequently attached to the face sheets. The pieces were held in place for the brazing cycle with a reusable fixture for high repeatability. The brazing cycle was performed with flowing $\mathrm{Ar}+3 \% \mathrm{H}_{2}$ gas in a vertical tube furnace consisting of a 20 minute hold at $450{ }^{\circ} \mathrm{C}$, to remove the organics from the braze tape followed by a 30 minute treatment at $1200{ }^{\circ} \mathrm{C}$ to join the pieces.

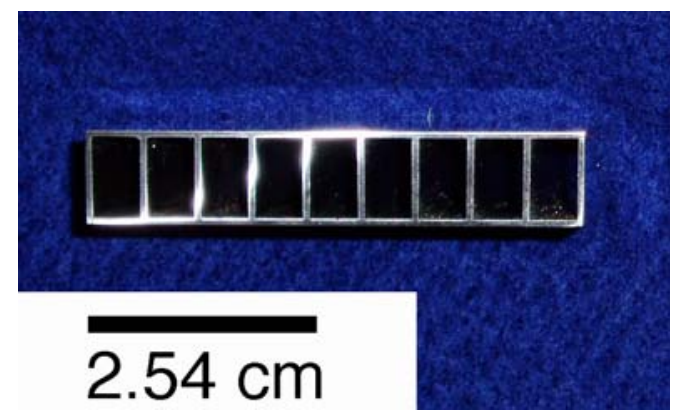

Figure 3. Cross section of rectangular channeled panel fabricated from X-750 alloy sheet.
The panel was subsequently aluminized via pack cementation using a high-activity pack with its aluminum source greater than $60 \mathrm{wt} \% \mathrm{Al}[7,12]$ using the process described by Das and coworkers [13]. The pack cementation is a chemical vapour deposition that does not require 'line-of-sight' to ensure that all surfaces are uniformly coated [14]. The pack and panel was contained in a stainless steel container. The pack contained 82 wt $\% \alpha-\mathrm{Al}_{2} \mathrm{O}_{3}(99.9 \%), 15 \mathrm{wt} \% \mathrm{Al}$ powder $(-40+325$ mesh, $99.8 \%)$, and $3 \mathrm{wt} \% \mathrm{NH}_{4} \mathrm{Cl}(99.5 \% \mathrm{~min})$. The container was inserted into a cold zone of the vertical tube furnace with flowing Ar. The container was moved to the hot zone and held for 1 hour at $950{ }^{\circ} \mathrm{C}$ then moved to a cold zone of the furnace until cool enough to handle. Following aluminization the panel was ultrasonically cleaned in acetone. The cleaned panel was placed in the tube furnace with flowing $\mathrm{Ar}+3 \% \mathrm{H}_{2}$ and annealed to homogenize the $\mathrm{Al}$ concentration through the thickness of the panel walls. A homogenization cycle to achieve $\mathrm{Al}$ homogenization within \pm 10 at $\%$ was devised as will be discussed in more detail.

For inspection, panel samples were mounted and polished using standard metallographic preparation techniques. An etching solution of $33 \% \mathrm{CH}_{3} \mathrm{COOH}, 33 \% \mathrm{H}_{2} \mathrm{O}, 33 \% \mathrm{HNO}_{3}$, and $1 \% \mathrm{HF}$ was used to reveal the $\gamma+\gamma^{\prime}$ microstructure. The microstructure was examined with a scanning electron microscope (SEM).

Microstructural evaluation was performed using a Hitachi S3200N SEM and a Phillips XL30 Field Emission Gun (FEG) SEM, both equipped with a removable backscatter electron (BSE) detector. Electron microprobe analysis (EMPA) via wavelength dispersive spectrometry (WDS) using a CAMECA SX100 was performed to determine elemental concentration profiles across the sample thickness and through joints. Vickers microhardness was determined using a Buehler Micromet II Digital Microhardness tester.

\section{Experimental Results}

\section{Brazed Panel}

The brazing was performed to standard specifications [11] with the exception that there was no annealing treatment on the panels after brazing for this study. However, after brazing and aluminization, the panels were subjected to a long annealing heat treatment, which is sufficient to homogenize the aluminum concentration. The limiting process is diffusion of the aluminum through the thickness of the samples, allowing the annealing step after brazing to be eliminated. There was good joint integrity between the $\mathrm{X}-750$ pieces.

\section{$\underline{\text { As-Aluminized Structure }}$}

SEM inspection of samples of the as-aluminized panel revealed high aluminum concentration layers on all surfaces of the samples. Comparing the nominal thickness of the panel before and after aluminization, the average thickness increase was only $1.8 \%$. The concentration profiles of the samples, compared with the Ni-Cr-Al ternary phase diagram, shown in Figure $4 \mathrm{a}$ (calculated with Pandat ${ }^{\mathrm{TM}}$ using the CompuTherm database) were used to assist with identification of the phases present. There 
were two layers on the samples, the outermost consisting of $\mathrm{Al}_{3} \mathrm{Ni}_{2}$ and $\beta-\mathrm{NiAl}$ with a $\beta-\mathrm{NiAl}$ innermost layer. The outermost layer was $90 \mu \mathrm{m}$ in thickness while the innermost layer was 30 $\mu \mathrm{m}$. The thickness of the deposited coating was consistent within $5-10 \mu \mathrm{m}$ on all surfaces of the panel, including the channels. Figure 5 shows the as-aluminized microstructure in the corner of a channel of the panel.

(a)
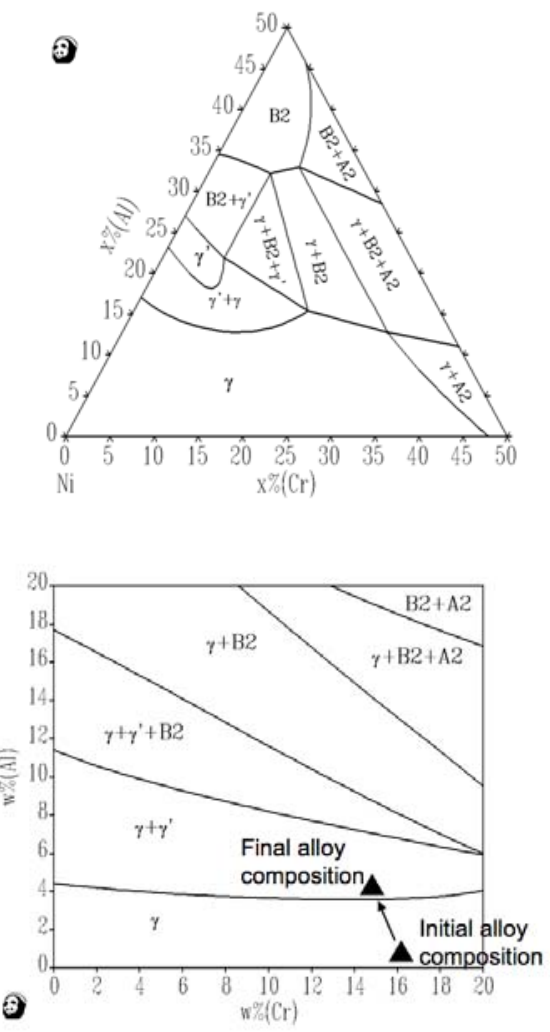

(b)

Figure 4. (a) Ni-Cr-Al ternary phase diagram at $1100{ }^{\circ} \mathrm{C}$. (b) Phase diagram for $\mathrm{X}-750$ at $1100{ }^{\circ} \mathrm{C}$ varying the aluminum and chromium at the expense of nickel. Both diagrams calculated with Pandat $^{\mathrm{TM}}$ using the CompuTherm database.

\section{Homogenization and Precipitation Strengthening}

From the EMPA concentration profiles and SEM images (in Figure 6) it is apparent that the panel had an increased concentration of aluminum through the sheet thickness from an initial level of 0.8 atomic $\%$ to a homogenized level of 9.6 atomic $\%$. To ensure the presence of $\gamma^{\prime}$ precipitates in the processed samples, the etched surfaces were examined and secondary electron (SE) images were taken. The panel components showed a fine precipitate microstructure in the $\gamma$ matrix with $\gamma^{\prime}$ precipitates approximately $100-150 \mathrm{~nm}$ in diameter, Figure 7. Hardness was measured through the thickness of the processed panel. The change in hardness from the bulk as-received material to the processed samples was $204 \pm 9 \mathrm{Hv}$ to $550 \pm 32 \mathrm{Hv}$.

\section{Discussion}

\section{Aluminization}

In this study the feasibility of strengthening wrought nickel-based sheet via pack aluminization for use in thermostructural panels is dependent on dimensions remaining nominally unchanged through the procedure. After the aluminization of the panel, the nominal thickness remained consistent with the panel after brazing, indicating primarily inward aluminum diffusion during the process, typical with high-activity pack aluminization [13]. It is also important that the aluminization achieved similar layer thicknesses on all parts of the panel to avoid any stress concentrations due to heterogeneous conditions in the panel [9]. This study has shown that both of these conditions were satisfied, demonstrating that this processing method is feasible.

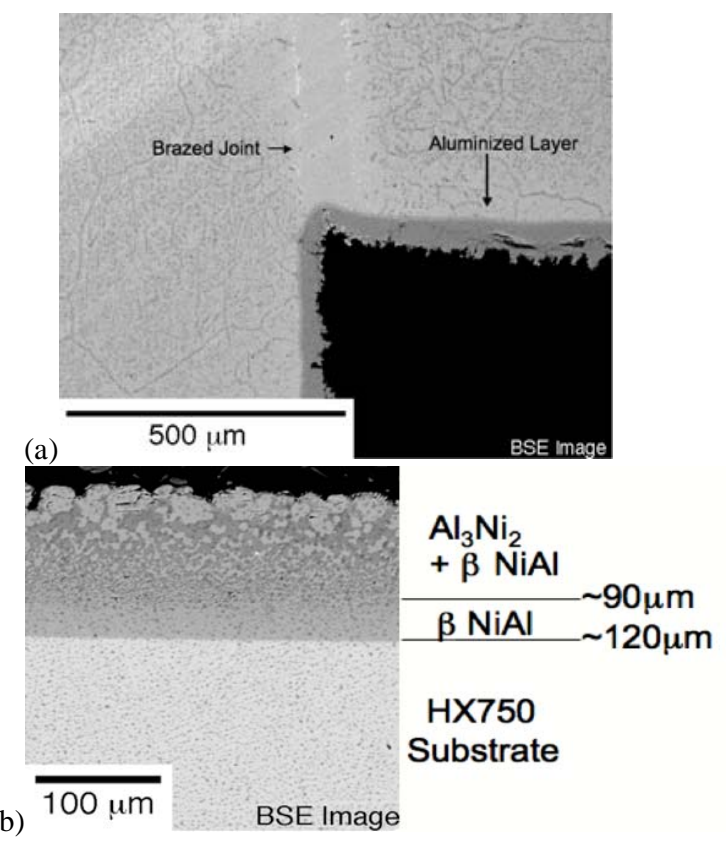

Figure 5. (a) BSE image of as-aluminized X-750 alloy fabricated panel. (b) Higher magnification of asaluminized microstructure.

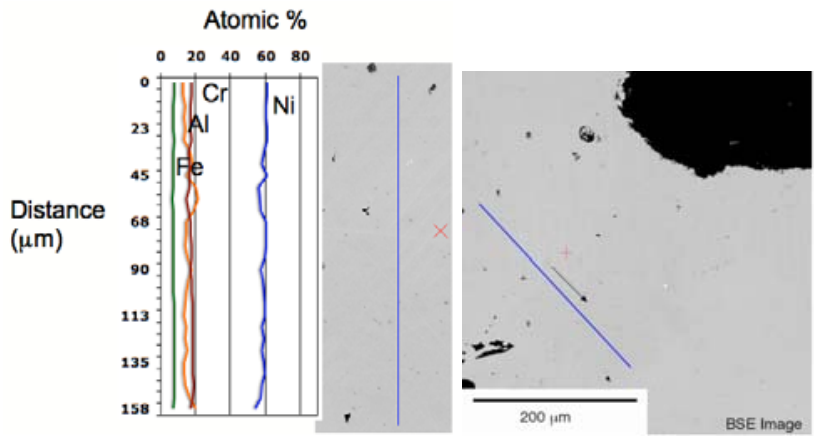

Figure 6. BSE image and EMPA concentration profiles of a joint in the aluminized and homogenized panel. 


\section{Homogenization}

Once the aluminum has been added to the samples, an annealing treatment is required to homogenize the aluminum concentration within 10 atomic percent through the thickness of the panel walls of $0.635 \mathrm{~mm}$. The homogenization time was estimated using a Fourier series approximation modeled for a composite slab and including the initial conditions consistent with this study [9].

$$
C(x, t)=C_{a v e}+\left(C_{c o a t}-C_{a v e}\right) \exp \left(\frac{-\pi^{2} D t}{l^{2}}\right)
$$

Where $\mathrm{C}_{\mathrm{ave}}$ is the average aluminum concentration over the entire thickness, $\mathrm{C}_{\text {coat }}$ is the aluminum concentration in coating, $\mathrm{D}$, the interdiffusion coefficient, and the parameter $l$ is half the thickness of the sample. Interdiffusion data for $\beta-\mathrm{NiAl}$ [15] and nickel solid solutions [16] were considered in calculating an estimate for the required annealing time. An interdiffusion coefficient of $\mathrm{D}=3.68$ x $10^{-15} \mathrm{~m}^{2} / \mathrm{s}$ was used to approximate an annealing time of 158 hours for a sheet thickness of $0.635 \mathrm{~mm}$. Examination of the samples after this annealing treatment by WDS confirmed that the aluminum concentration was homogenized through the thickness of the panel components.

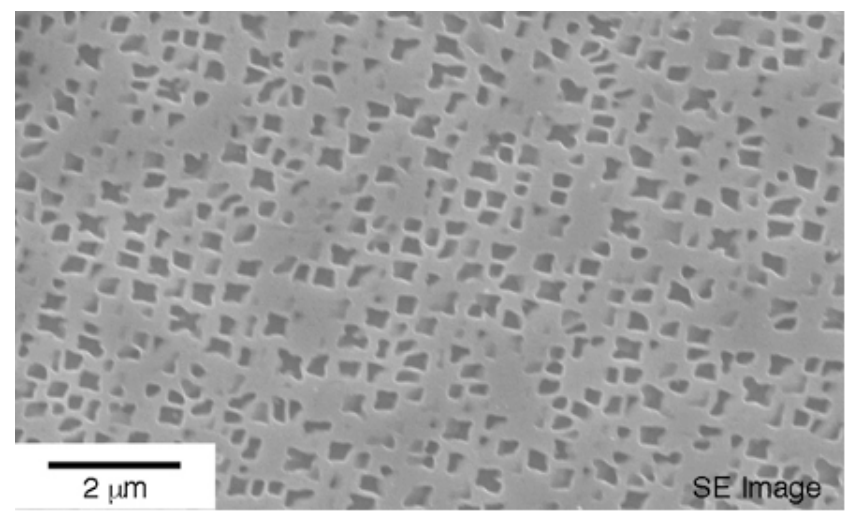

Figure 7. SE image the center of a X-750 panel component after aluminization and homogenization.

Choosing an appropriate starting material to avoid undesirable phase fields is also an important consideration. Assessments of phase diagrams and shifts with $\mathrm{Al}$ concentration using thermodynamic databases and software such as Pandat ${ }^{\mathrm{TM}}$ can be helpful for the selection of the starting sheet alloy. For example, an alloy containing molybdenum, such as INCONEL® 625, will form the $\sigma$ phase [17] with additions of $\mathrm{Al}$, while an alloy with large amounts of chromium, such as INCONEL ${ }^{\circledR}$ 693, will precipitate $\alpha-\mathrm{Cr}$ during the aluminization process due to its low solubility in the $\beta-\mathrm{NiAl}$ coating [18]. The $\mathrm{X}-750$ composition is well suited to this processing path due to the fact that when varying the $\mathrm{Al}$ and $\mathrm{Cr}$ concentrations at expense of $\mathrm{Ni}$, there are not any undesirable phase fields between the $\gamma^{\prime}$ and B2 phases, Figure 4b.

\section{Precipitation Strengthening}

The very fine $\gamma-\gamma^{\prime}$ microstructure of the panel, Figure 7 , resulted from air quenching, without any attempt to optimize the size of the $\gamma^{\prime}$ precipitates. Typically $\gamma+\gamma^{\prime}$ precipitation strengthened alloys used in aerospace applications have precipitates in the size ranging from $350 \mathrm{~nm}$ to $600 \mathrm{~nm}$ [17]. The average size of the precipitates in this study is approximately $150-200 \mathrm{~nm}$. Although these precipitates are smaller than what is typically desirable, it is possible to coarsen the precipitates with further annealing at intermediate temperatures to achieve the optimum sizing. The increase in hardness of the panel was achieved by the Al-diffusion into the matrix and forming the observed $\gamma+\gamma^{\prime}$ microstructure [17]. Thus it is anticipated that further hardening would be possible with optimization of the precipitate size.

\section{Conclusions}

A panel with rectangular channels was fabricated by brazing wrought X-750 alloy sheet in a fixture to ensure proper geometry. Aluminization via pack cementation successfully created a layer of high aluminum concentration near the surface of the original refractory-lean, non-precipitation hardened alloy without any significant change in dimensions. Annealing of the aluminized specimens homogenously distributed the aluminum through the $0.635 \mathrm{~mm}$ thick panel walls transforming the initially formable material into a stronger, $\gamma+\gamma^{\prime}$ precipitation hardened alloy. Thus it has been demonstrated that a solid solution Ni-based alloy can be fabricated into a panel and subsequently processed to achieve a precipitation strengthened $\mathrm{Ni}$ alloy in a previously unattainable geometry.

\section{Acknowledgments}

The authors appreciate the assistance of Chris Torbet and Dipak Das for helpful discussions and assistance with experimental procedures as well as the assistance of Steve Emanuel for machining operations. The support of the Office of Naval Research (Grant\#N00014-05-1-0439) is gratefully acknowledged.

\section{References}

1. N. Wicks, J.W. Hutchinson, "Optimal Truss Plates," International Journal of Solids and Structures, 38 (2001), 51655183

2. A.G. Evans, J.W. Hutchinson, N.A. Fleck, M.F. Ashby, and H.N.G. Wadley, "The topological design of multifunctional cellular metals," Progress in Materials Science, 46 (2001), 309327.

3. L. Valdevit, J.W. Hutchinson, A.G. Evans, "Structurally optimized sandwich panels with prismatic cores," International Journal of Solids and Structures, 41 (2004), 5105-5124.

4. M.V. Nathal, J.D. Whittenberger, M.G. Hebsur, P.T. Kantzos, and D.L. Drause, "Superalloy lattice block structures," Superalloys 2004 eds. K.A. Green, T.M. Pollock, H. Harada, T.E. Howson, R.C. Reed, J.J. Schirra, and S. Walston, (Warrendale, PA, TMS, 2004) 431-439.

5. S. Hyun, A.M. Karlsson, S. Torquato, and A.G. Evans, "Simulated properties of Kagomé and tretragonal truss core panels," International Journal of Solids and Structures, 40 (2003), 6989-6998. 
6. F.W. Zok, H.J. Rathbun, Z. Wei, and A.G. Evans, "Design of metallic textile core sandwich panels," International Journal of Solids and Structures, 40 (2003), 5707-5722.

7. R. Streiff, J.M. N'Gandu Muamba, and D.H. Boone, "Surface morphology of diffusion aluminide coatings" Thin Solid Films, 119 (1984), 291-300.

8. D.C. Tu and L.L. Seigle, "Kinetics of formation and microstructure of aluminide coatings on Ni-Cr alloys," Thin Solid Films, 95 (1982), 47-56.

9. M.E. Glicksman, Diffusion in Solids: Field Theory, Solid-State Principles, and Applications (John Wiley \& Sons, New York, 2000).

10. Haynes X750 alloy specifications, Haynes International Inc, 2004.

11. AMDRY DF-6A braze specifications, Sulzer Metco, 2000.

12. P. Shen, D. Gan, and C.C. Lin, "Microstructures and crystallographic relationships in aluminized coatings on René 80," Materials Science and Engineering, 78 (1986), 171-178.
13. D.K. Das, V. Singh, and S.V. Joshi, "Evolution of aluminide coating microstructure on nickel-base cast superalloy CM-247 in a single-step high-activity aluminizing process," Metallurgical and Materials Transactions A, 29A (1998), 2173-2188.

14. R. Mévrel, C. Duret, and R. Pichoir, "Pack Cementation Processes," Materials Science and Technology, 2 (1986), 201206.

15. N. Voudouris, C. Christoglou, and G.N. Angelopoulos, "Formation of aluminide coatings on nickel by a fluidized bed CVD process," Surface and Coatings Technology, 141 (2001), 275-282.

16. M. Watanabe et al., "Electron microscopy study of $\mathrm{Ni} / \mathrm{Ni}_{3} \mathrm{Al}$ diffusion-couple interface0II. Diffusivity measurement," Acta Metallurgica et Materialia, 42 (1994), 3389-3396.

17. M. Durand-Charre, The Microstructure of Superalloys (Singapore: Gordon and Breach, 1997).

18. W.H. Tian, C.S. Han, and M. Nemoto, "Precipitation of $\alpha-C r$ in B2-ordered NiAl," Intermetallics, 7 (1999), 59-67. 